\title{
Characterizations and Modeling the Influence of Particle Size Distributions (PSD) of Glass Powder on the Mechanical Behavior of Normal Strength Concrete
}

\author{
Brwa Omer*, Jalal Saeed \\ Department of Civil Engineering, College of Engineering, University of Sulaimani, Sulaymaniyah, 46001, Kurdistan Region of Iraq
}

Received July 20, 2020; Revised September 16, 2020; Accepted September 29, 2020

\section{Cite This Paper in the following Citation Styles}

(a): [1] Brwa Omer, Jalal Saeed, "Characterizations and Modeling the Influence of Particle Size Distributions (PSD) of Glass Powder on the Mechanical Behavior of Normal Strength Concrete," Civil Engineering and Architecture, Vol. 8, No. 5, pp. 993 - 1005, 2020. DOI: 10.13189/cea.2020.080526.

(b): Brwa Omer, Jalal Saeed (2020). Characterizations and Modeling the Influence of Particle Size Distributions (PSD) of Glass Powder on the Mechanical Behavior of Normal Strength Concrete. Civil Engineering and Architecture, 8(5), 993 - 1005. DOI: 10.13189/cea.2020.080526.

Copyright $\bigcirc 2020$ by authors, all rights reserved. Authors agree that this article remains permanently open access under the terms of the Creative Commons Attribution License 4.0 International License

\begin{abstract}
In this study, a comprehensive experimental investigation and modeling were carried out to examine the impact of two different grain size distributions of glass powder (GP) $((55 \mu \mathrm{m}<$ GP-A $<135 \mu \mathrm{m})$ and $(55 \mu \mathrm{m}>$ GP-B)) in various percentages up to $30 \%$ on the mechanical characteristics of concrete at different testing ages $(7,28,56$, and 91 days). The experimental data observed were utilized to develop different models for characterizing the compressive, splitting, and flexural strength behavior of concrete modified with GP. Results indicated that, up to $25 \%$ of cement replacement with GP, the difference in particle size of GP does not have a substantial impact on the mechanical performance of concrete if it is less than $135 \mu \mathrm{m}$. Irrespective of GP particle size and the curing days, the increasing percentage of GP replacement up to $10 \%$ for compressive strength and up to $15 \%$ for splitting and flexural tensile strength tends to marginally reduce compressive, splitting, and flexural tensile strength at 28 days by $4 \%, 8 \%$, and $6 \%$, respectively. The developed models were found to be well predicted by curing ages, water to binder ratio $(\mathrm{w} / \mathrm{b})$, and GP content. Based on the model parameters, the percentage of GP to partially replace cement is much more effective than the particle size of GP, w/b, and curing time in changing the mechanical properties of normal strength concrete. The analytical results were in good agreement with the experimental investigation.
\end{abstract}

Keywords PSD, Glass Powder Content, Curing Time,
Cement Replacement, Strengths, Modelling

\section{Introduction}

Concrete is currently considered to be the most frequently used building material. It is also considered as the world's second most frequently used material after water [1]. According to Glavind [2], each year, almost 10,000 million tons of concrete have been used, and this amount will keep growing.

Cement manufacturing is considered as one of the primary industrial sectors contributing to releasing carbon dioxide emissions into the atmosphere, accounting for about $8 \%$ of global annual carbon emissions [3]. Nayana and Kavitha [4] reported that the production of cement is $2.5 \%$ rising annually, and between 2006 and 2050 the amount of its production is expected to rise from 2.55 billion tonnes to 3.7-4.4 billion tonnes. Consequently, the amount of $\mathrm{CO}_{2}$ emissions will be effectively increased. It is clear, therefore, that a successful approach for decreasing the environmental footprint of the industry is the use of alternative or cementing materials as partial cement substitution ( $\mathrm{SCMs}$ ).

Due to its chemical composition, which is rich in silica content and amorphous phases of silica, waste glass in the powder form can act as a pozzolanic material in the 
hydrating cement environment to provide a product that has certain characteristics of Portland cement. [5]. As a result, utilizing GP to replace a partial amount of cement powder can have various environmental benefits.

Various research has been conducted to investigate the possibility of using GP waste to replace cement [6-10]. It has been shown that the viability of GP as a cement substitution depends on its pozzolanic reactivity, which in turn depends on several factors such as chemical compositions, degree of crystallinity (amorphousness degree), grain size distributions and specific surface area, and percentage level of GP used as cement replacement.

Among these factors and for the mechanical properties of concrete, considerable attention has been paid to the grain size distributions and percentage replacement of GP. Mechanically, the effect of these two factors can be evaluated by using a strength activity index.

Ramezanianpour [11] pointed out, the pozzolanic activity of any pozzolanic materials can be evaluated mechanically by using the strength activity index as it is described in ASTM (C 311). Bignozzi et al. [12] have stated that the pozzolanic reactivity of the addition can be assessed by using the activity index, which must be greater than or equal to $75 \%$ at 28 days of curing.

Investigations have shown that the particle size distribution of GP has a significant effect on the different concrete properties. This is because of its direct effect on Alkali-Silica Reaction (ASR) occurrence in concrete. The probability of ASR expansion in concrete can be reduced when particle sizes of GP used decreased [8, 14]. Reference to Federico and Chidiac [13] reveal that the pozzolanic behavior of GP was firstly observed at particle sizes approximately less than $300 \mu \mathrm{m}$. Kalakada and Doh [15] reported that the pozzolanic properties of GP are similar to those of other materials like metakaolin, silica, and fly ash [16, 17], enables GP to have a suppressive effect on the ASR development in concrete. Based on the experimental investigations, Kalakada and Doh [15] also, stated that the glass with particle sizes of approximately $300 \mu \mathrm{m}$ exhibited insignificant ASR occurrence, which is consistent with a maximum particle size of $300 \mu \mathrm{m}$ for ASR occurrence that indicated by $[14,18,19,20]$.

A study by Shi et al. [7] and Schwarz and Neithalath [21] observed that, after 90 days of curing, the pozzolanic reactivity of GP could be higher than fly ash when using low percent replacement levels of GP with particles less than $100 \mu \mathrm{m}$. However, other researchers have reported that the favorable particle size of GP to be considered as a pozzolanic material is $75 \mu \mathrm{m}$ or less [22-24, 45]. Meyer et al. [25] contended, however, that glass below 45 microns could become pozzolanic.

Shao et al. [8] observed the size effect of GP when three different particle sizes $(150 \mu \mathrm{m}, 75 \mu \mathrm{m}$, and $38 \mu \mathrm{m})$ of the same type of GP were used as a partial replacement of cement. The percentage replacement of cement by GP was $30 \%$ by volume. They indicated that the increase of the particle size of GP tends to the decreasing of the compressive strength. Shi et al. [7] evaluated the pozzolanic behavior of four waste GP from a glass beads manufacturer to replace cement by $20 \%$. They noticed that the finely ground GP showed very high pozzolanic activity. Mirzahosseini and Riding [26] indicated that GP with a size of particles between 0 to $25 \mu \mathrm{m}$ was shown to have increased strength activity and more portlandite consumption compared to GP with a size 25 to $38 \mu \mathrm{m}$ and 63 to $75 \mu \mathrm{m}$. Recently, Jiang et al. [27] used GP having different particle sizes $(75 \mu \mathrm{m}$ and $150 \mu \mathrm{m})$ and substitutions (up to $80 \%$ by weight of cement) to experimentally study the pozzolanic behavior of GP at various testing ages $(7,28$, and 91 days). They observed that there is a linear reduction in both compressive and splitting tensile strength with the increased replacement percentage. Also, both the particle size of GP showed almost similar compressive strength at respect ages of the test. The strength reduction in high weight/volume replacement is attributed to the lack of Calcium Hydroxide $(\mathrm{CH})$, which is essential for the production of secondary Calcium Silicate Hydrate during the pozzolanic reactivity process [28].

A review of past studies indicates that there is no agreement on the optimal GP percentage to replace cement. The reason could be because the pozzolanic behavior of GP relies on several factors, as previously stated. Besides, a comprehensive study has not been conducted to investigate and quantify the effects of GP particle sizes and content, water to binder ratio, and curing time on the compressive, splitting, and flexural tensile strength of concrete. The paper aims (i) to characterize the effect of the particle size distributions (PSD) and various percentage amounts of waste GP used to partially replace cement by weight on the mechanical characteristics of concrete at different curing times. (ii) To quantify the effect of various independent variables governing the mechanical behavior of concrete modified with glass powder (GP-concrete).

\section{Materials and Methods}

\subsection{Material Properties}

\subsubsection{Cement}

The cement type used was ordinary Portland cement (OPC) from the Tasluja Cement Co. (Iraq, Kurdistan-Region, Sulaimani City, North of Iraq, $35.6265^{\circ}$ $\mathrm{N}$, and $\left.45.2119^{\circ} \mathrm{E}\right)$ with a strength grade of $(42.5 \mathrm{R})$ complying with Iraqi standard (IQS/5/1984) [29]. The chemical and mineralogical compositions of used cement and GP are presented in Table 1. With the use of Laser Particle Analyzer, the grading curve of cement was also determined (Figure 1). 


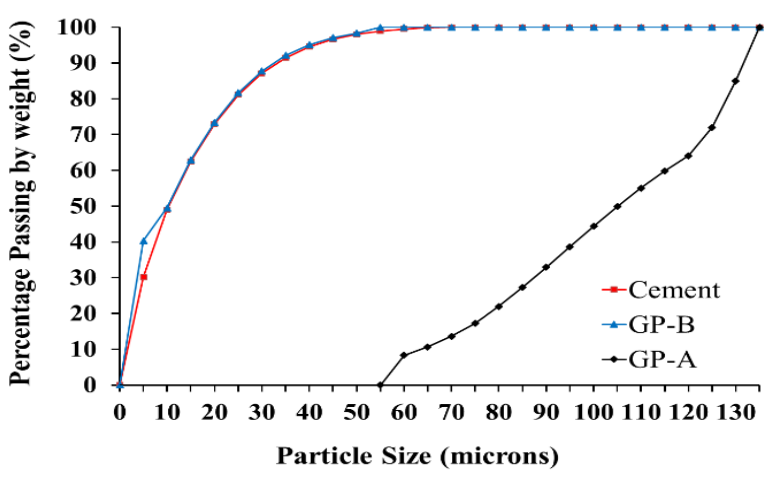

(a)
GP-B

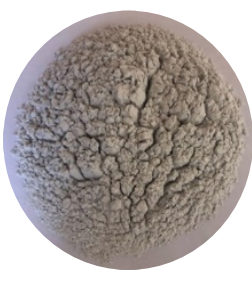

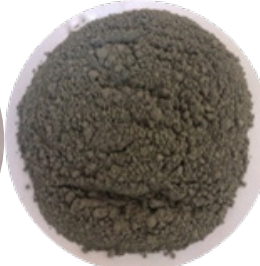

Cement

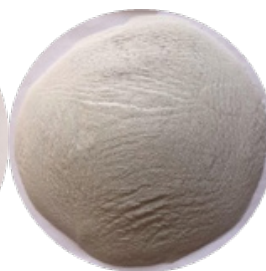

GP-A (b)

Figure 1. (a) Particle size distribution curves of cement, GP-A, and GP-B, (b) Waste glass powder after milling and cement used in this study.

\subsubsection{Fine aggregate (Sand)}

Washed river sand of (Ranya district in Sulaimani Governorate located in the Northeast of the Kurdistan Region of Iraq, $35^{\circ} 33^{\prime} 0^{\prime \prime} \mathrm{N}$, and $45^{\circ} 26^{\prime} 0^{\prime \prime} \mathrm{E}$ ) was used. It is bulk specific gravity (SSD), and dense-dry density values were 2.69 and $1875 \mathrm{~kg} / \mathrm{m}^{3}$, respectively. It was prepared according to graded sand requirements ASTM C136 [30] specification.

\subsubsection{Coarse aggregate (Gravel)}

Crushed gravel from (Piramagrun town, northwest of
Sulaimani city- Kurdistan region of Iraq) was used with a nominal max. size of $12.5 \mathrm{~mm}$, bulk specific gravity (SSD)- of 2.49, and dense-dry density of $1600 \mathrm{~kg} / \mathrm{m}^{3}$. The physical tests were carried out according to ASTM designations. The grain size distribution of both sand and gravel was performed and confirmed with ASTM C136 [30] and ASTM C33 [31] standard specification (Figure 2).

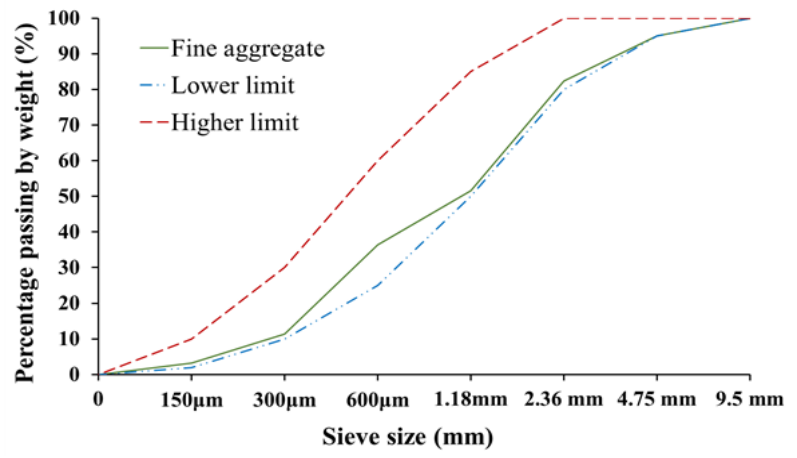

(a)

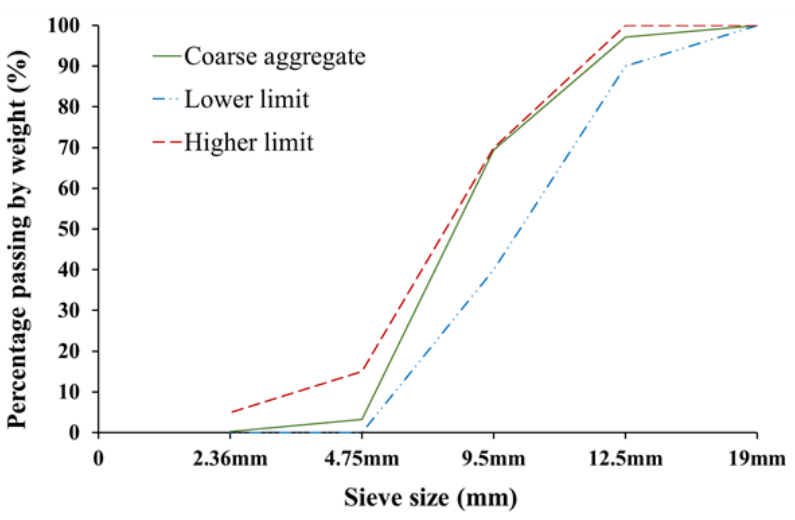

(b)

Figure 2. Grain size distribution for aggregates according to ASTM C33 limits. (a). Sand and (b). Gravel

Table 1. Chemical composition for Tasluja Cement and glass powder (GP) with requirements of ASTM C618 for pozzolans used in this study

\begin{tabular}{|c|c|c|c|c|}
\hline Chemical Composition & Chemical Formula & OPC (\%) & GP (\%) & ASTM- C618 \\
\hline Lime & $\mathrm{CaO}$ & 61.66 & 9.868 & \\
\hline Silica & $\mathrm{SiO}_{2}$ & 19.83 & 74.03 & \\
\hline Alumina & $\mathrm{Al}_{2} \mathrm{O}_{3}$ & 4.48 & 1.023 & \\
\hline Ferrite & $\mathrm{Fe}_{2} \mathrm{O}_{3}$ & 2.32 & 0.108 & \\
\hline Magnesia & $\mathrm{MgO}$ & 3.14 & 4.739 & \\
\hline Sulfur trioxide & $\mathrm{SO}_{3}$ & 2.57 & 0.13 & \\
\hline Potassium oxide & $\mathrm{K}_{2} \mathrm{O}$ & 0.68 & 0.198 & \\
\hline Sodium oxide & $\mathrm{Na}_{2} \mathrm{O}$ & 0.19 & 8.024 & \\
\hline Loss on Ignition & LOI & 1.5 & 1.83 & \\
\hline Tricalcium silicate & $\mathrm{Ca}_{3} \mathrm{SiO}_{5}$ & 59.50 & & \\
\hline Dicalcium silicate & $\mathrm{Ca}_{2} \mathrm{SiO}_{4}$ & 11.98 & & \\
\hline Aluminate Tricalcium & $\mathrm{Ca}_{3} \mathrm{Al}_{2} \mathrm{O}_{6}$ & 7.95 & & \\
\hline Tetracalcium Aluminoferrite & $\mathrm{Ca}_{4} \mathrm{Al}_{2} \mathrm{Fe}_{2} \mathrm{O}_{10}$ & 7.05 & & \\
\hline \multicolumn{2}{|c|}{$\mathrm{SiO} 2+\mathrm{Al} 2 \mathrm{O} 3+\mathrm{Fe} 2 \mathrm{O} 3$, min. $\%$} & & 75.16 & 70 \\
\hline \multicolumn{2}{|c|}{ SO3, max. $\%$} & & 0.13 & 4 \\
\hline \multicolumn{2}{|c|}{ Moisture content, max. \% } & & - & 3 \\
\hline \multicolumn{3}{|c|}{ Loss on ignition, $\max$. } & 1.83 & 10 \\
\hline
\end{tabular}




\subsubsection{Glass powder (GP)}

The GP used was obtained from local waste windows building glasses, which are typically well-known as soda-lime glass. For preventing the undesirable effect of alkali-silica reaction and getting the acceptable pozzolanic behavior, the waste glass was ground to pass a $140 \mu \mathrm{m}$ sieve. For this purpose, it was being crushed and ground by a ball mill in the laboratory. The milled glass was then sieved to have the preferred particle sizes as shown in Figure $1 b$. To evaluate the effect of the particle size of the same GP, two different particle sizes were used (GP-A and GP-B); (GP-A) having particles passing (140-micron) sieve and retained on (56 microns) sieve. While (GP-B) having particles passing sieve No. 230 (63 microns). The chemical analysis of the GP used was determined by the XRF technique (Table 1). The grain size distribution curves of GP were also determined using Laser Particle Analyzer, as shown in Figure 1; and it was found that GP-B has particle sizes of less than $55 \mu \mathrm{m}$. The specific gravity of GP was found to be 2.51 and 2.505 for GP-A and GP-B, respectively. These values are far less than 3.15 for used OPC. Following ASTM C 618 specifications [44], as shown in Table 1, the GP is likely to work as a desirable replacement for cement.

\subsection{Experimental Program}

The experimental program mainly involves two parts. The first part includes investigating the influences of partially replacing cement with GP having two different particle sizes on different strength characteristics of concrete. In the second part, based on the obtained data from the first part, the effect of various independent variables governing the mechanical behavior of GP-modified concrete was quantified and discussed.

\subsection{Mixture Proportion and Preparation}

For achieving the objective of the research work, thirteen mixtures were prepared. Details for each mixture are described in Table 2. Mixes were prepared using an electric tilting mixer with a capacity of $0.08 \mathrm{~m}^{3}$ following ASTM C192 [32] standard procedures. Before the mixing process and for each mixing batch, the glass powder was mixed thoroughly with cement.

\subsection{Curing and Testing Method}

All specimen samples were made and cured under ASTM C192 [32] standard specifications. A universal testing machine (CONTROLS type) was used to test concrete cylinders with $(100 \times 200) \mathrm{mm}$ for compressive and splitting tensile strength and prisms with $(100 \times 100 \times 500) \mathrm{mm}$ for flexural strength. The loading rate used to test compressive strength, splitting tensile strength, and flexural strength were $0.3 \mathrm{MPa} / \mathrm{s}, 0.023 \mathrm{MPa} / \mathrm{s}$., and $0.02 \mathrm{MPa} / \mathrm{s}$. respectively.

\subsection{Experimentally Observed Data}

A total of 78 data points from experimental work were observed; 52 data points from the compressive strength test, 13 data points from the tensile splitting strength test, and 13 data points from the flexural strength test. Each data point is based on an average value of three measured data of the same concrete specimens. The above data includes measurements for concrete samples without GP.

Table 2. Mixture proportion for $1 \mathrm{~m}^{3}$ of concrete

\begin{tabular}{|c|c|c|c|c|c|c|c|c|c|}
\hline \multirow{2}{*}{\multicolumn{2}{|c|}{$\begin{array}{l}\text { Specimen } \\
\text { Details }\end{array}$}} & \multirow{2}{*}{$\begin{array}{c}\text { Cement } \\
(\mathrm{kg})\end{array}$} & \multicolumn{2}{|c|}{ Sand (SSD) (kg) } & \multirow{2}{*}{$\begin{array}{c}\text { Gravel (SSD) } \\
(\mathrm{kg})\end{array}$} & \multirow{2}{*}{$\begin{array}{l}\text { Water } \\
\text { (kg) }\end{array}$} & \multicolumn{2}{|c|}{ GP } & \multirow{2}{*}{$\begin{array}{c}\text { Water/binder } \\
(\mathbf{W} / \mathbf{C}+\mathbf{G P})\end{array}$} \\
\hline & & & GP-A & GP-B & & & $\%$ & (kg) & \\
\hline \multicolumn{2}{|c|}{$\mathrm{CR}$} & 331.0 & \multicolumn{2}{|c|}{929.93} & 848.0 & 188.67 & & - & 0.57 \\
\hline A5 & B5 & 314.5 & 926.30 & 926.26 & 848.0 & 188.67 & 5 & 16.55 & 0.57 \\
\hline A10 & B10 & 297.9 & 922.72 & 925.34 & 848.0 & 188.67 & 10 & 33.10 & 0.57 \\
\hline A15 & B15 & 281.3 & 919.12 & 919.01 & 848.0 & 188.67 & 15 & 49.65 & 0.57 \\
\hline $\mathrm{A} 20$ & B20 & 264.8 & 915.52 & 915.37 & 848.0 & 188.67 & 20 & 66.2 & 0.57 \\
\hline A 25 & B25 & 248.2 & 911.91 & 911.74 & 848.0 & 188.67 & 25 & 82.75 & 0.57 \\
\hline $\mathrm{A} 30$ & B30 & 231.7 & 908.31 & 908.10 & 848.0 & 188.67 & 30 & 99.3 & 0.57 \\
\hline
\end{tabular}




\subsection{Modeling}

\subsubsection{Non-linear models}

Regression analysis was made to develop different non-linear models to predict compressive, splitting, and flexural strength of GP-concrete. The primary independent parameters considered in the regression analysis were compressive strength of reference normal concrete $f \bar{c}_{(N C)}$, water to binder ratio (w/b), percentage of GP (GP\% by weight of cement), and curing ages ( $t$ ). Based on the proposed models, the effects of these independent parameters on the mechanical properties of the concrete are quantified.

\subsubsection{Vipulanandan and Hoek-Brown correlation models}

Based on the analysis of the experimental data, Vipulanandan correlation model [33-35] (Eq.1) and Hoek-Brown correlation model [36, 37] (Eq. 2), can be successfully used for predicting and correlating the splitting tensile and the flexural tensile strength with the compressive strength of concrete modified with GP.

$$
\begin{gathered}
Y=k+\frac{x}{n+m * x} \\
Y=x+q\left(r * \frac{x}{q}+s\right) v
\end{gathered}
$$

in which $Y$ in both Equations is the dependent variable (splitting strength $\left(F_{t_{(G P)}}\right)$ or flexural strength $\left.\left(F_{r_{(G P)}}\right)\right), k$, $n, m$, are the model parameters of Eq. 1, $x$ in both Equations is the independent variable (compressive strength of GP-concrete $\left.F \bar{c}_{(G P)}\right) . q, r, s, v$, are the model parameters for Eq. 2.

\subsubsection{Model prediction accuracy}

The coefficient of determination $\left(\mathrm{R}^{2}\right)$, Root Mean Squared Error (RMSE), Mean Absolute Error (MAE), Mean Absolute Percentage Error (MAPE), and Integral absolute error (IAE) were used as the prediction accuracy.

$$
\begin{gathered}
R^{2}=\left(\frac{\left(\sum_{i=1}^{n}\left(m_{i}-\bar{m}_{i}\right)\left(p_{i}-\bar{p}_{i}\right)\right)}{\sqrt{\sum_{i=1}^{n}\left(m_{i}-\bar{m}_{i}\right)^{2} \sum_{i=1}^{n}\left(p_{i}-p_{i}\right)^{2}}}\right)^{2} \\
R M S E=\sqrt{\frac{\sum_{i=1}^{n}\left(m_{i}-p_{i}\right)^{2}}{n}} \\
I A E=\sum \frac{\left[\left(m_{i}-P_{i}\right)^{2}\right]^{\frac{1}{2}}}{\sum m_{i}} \cdot 100 \\
M A E=\frac{\sum_{i=1}^{n}\left|m_{i}-p_{i}\right|}{n} \\
M A P E=\frac{1}{n} \sum_{i=1}^{n}\left|\frac{m_{i}-P_{i}}{m_{i}}\right|
\end{gathered}
$$

Where:

$m_{i}=$ Observed data; $\bar{m}_{i}=$ Average of observed data

$p_{i}=$ Predicted data; $\bar{p}_{i}=$ Average of predicted data;

$n=$ Number of data

\section{Results and Discussions}

\subsection{Experimental Results}

\subsubsection{Compressive strength (ASTM C39 [38])}

Figures 4 through 7 present the results of the compressive strength test for concrete containing different percentages (5\% to $30 \%$ ) and particle sizes (GP-A and GP-B) of GP to replace cement at several testing days $(7,28,56$, and 91). From Figures 4 and 5, it can be generally noticed that whatever the curing age and particle sizes of GP, the use of GP tends to decrease the compressive strength of specimens. However, with increase GP content from $5 \%$ to $\% 10$, the compressive strength of the specimens decreased marginally relative to the control specimens. Beyond 10\% GP replacement, the compressive strength of the concrete specimens has progressively decreased. The gradual reduction in compressive strength was due to the increased amount of water with an increased GP percentage replacement, which was not used for hydration reaction. Furthermore, as GP substitution increases, the amount of cement content is reduced, resulting in a small quantity of calcium hydroxide $(\mathrm{CH})$ being produced during the hydration reaction [41]. At the early age of strength development (7 days of testing), the compressive strength of specimens contains GP-A (up to $10 \%$ ) is relatively higher than those of GP-B but similar to the control specimen (Figures 6 and 7). The reason could be due to the positive action of that type of GP (GP-A) as a filler material.

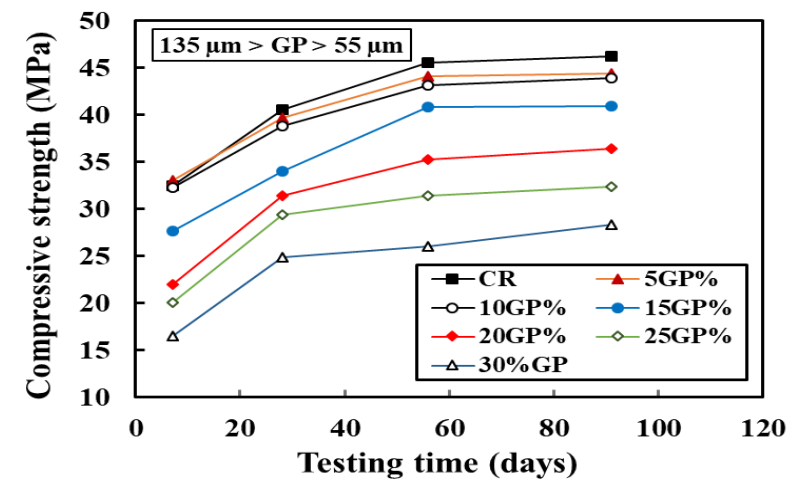

Figure 4. Influence of curing age on the compressive strength of GP-A modified concrete

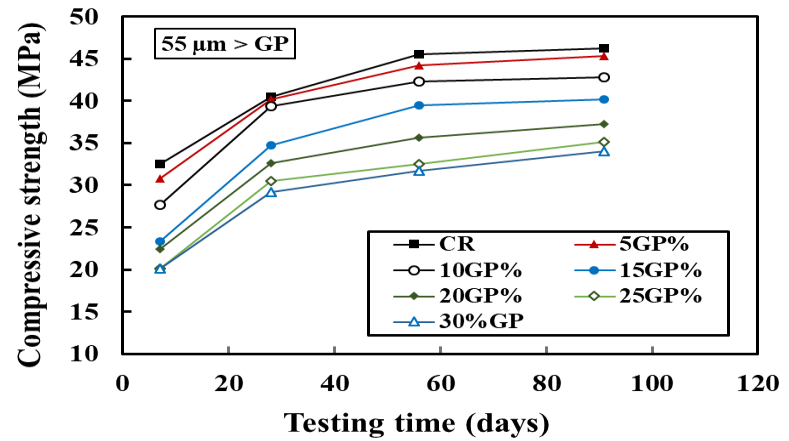

Figure 5. Influence of curing age on the compressive strength of GP-B modified concrete 


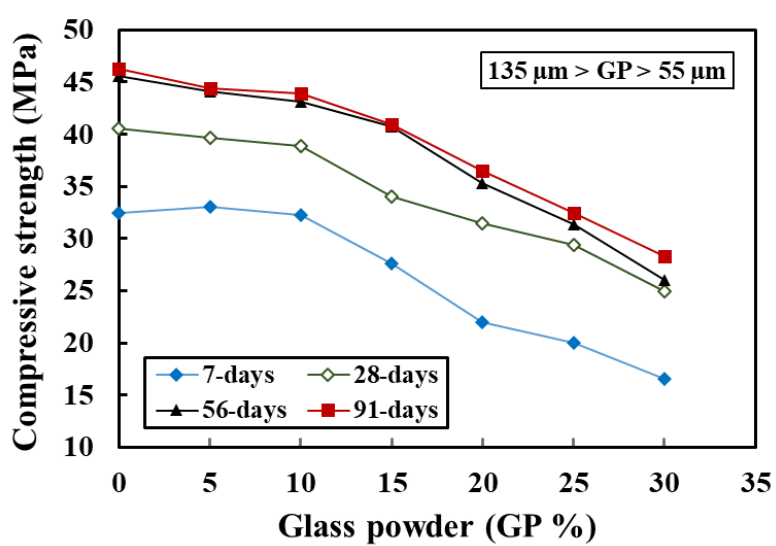

Figure 6. Impact of GP-A on concrete compressive strength at various ages

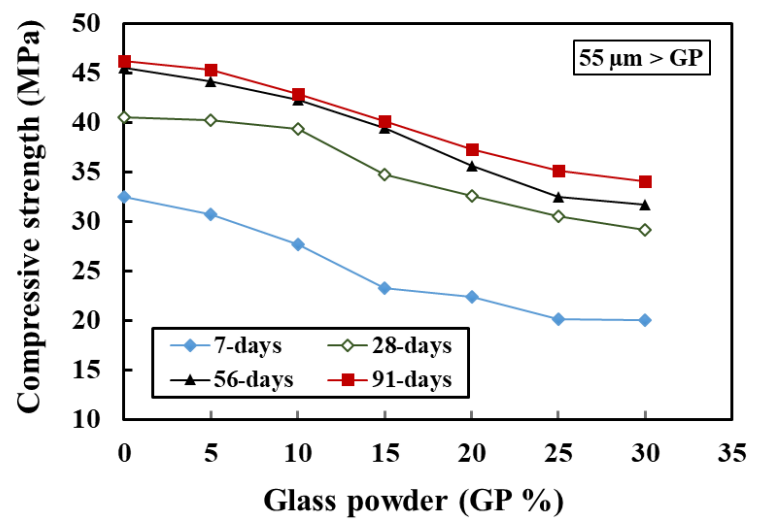

Figure 7. Impact of GP-B on concrete compressive strength at various ages

Considering strength activity (activity index) recommended by ASTM C618 for evaluating the pozzolanic activity of GP-concrete at 28 days of curing, up to $25 \%$ for GP-B and up to $20 \%$ for GP-A can be considered and used as a pozzolanic material as shown in Figures 8 and 9.

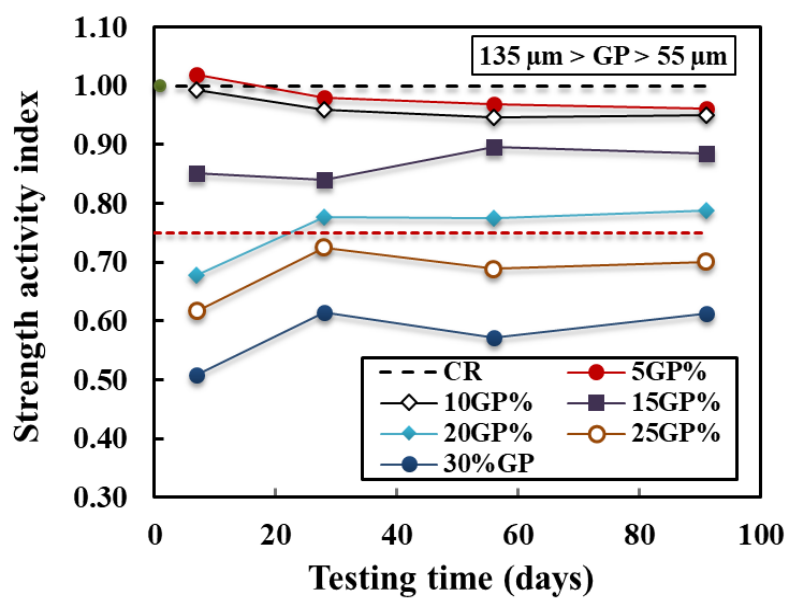

Figure 8. Effect of GP-A on strength activity index.

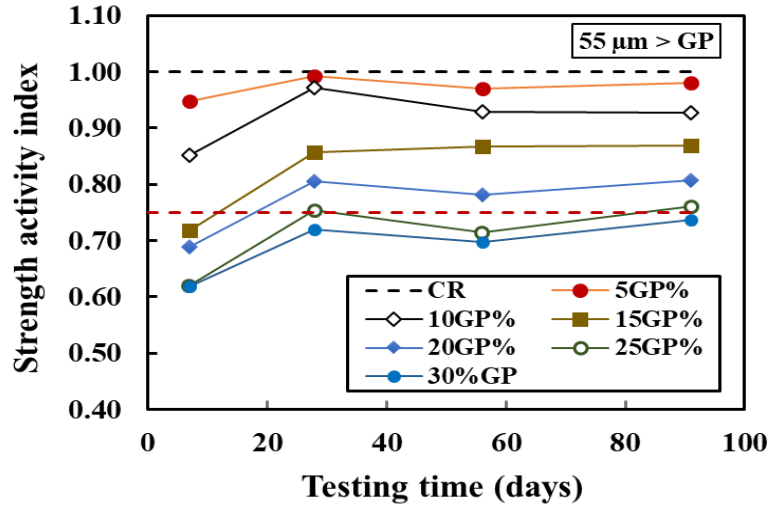

Figure 9. Effect of GP-B on strength activity index.

Although GP-B has smaller particle sizes than GP-A, up to $25 \%$ of the replacement and at different curing ages except for 7 days, the compressive strength values obtained from both particle sizes were almost close to each other. This implies that the size effect of GP on the compressive strength does not contribute significantly. This observation is in agreement with findings by Letelier et al. [40]. They found that the size of GP has a more significant effect on the physical properties such as absorption, porosity, and capillarity of mortar than on the mechanical properties. However, considering the development of compressive strength values from 7 to 91 days of curing, it can be found that the pozzolanic reactivity of smaller particle size (GP-B) is relatively higher than that of GP-A (Figure 10).

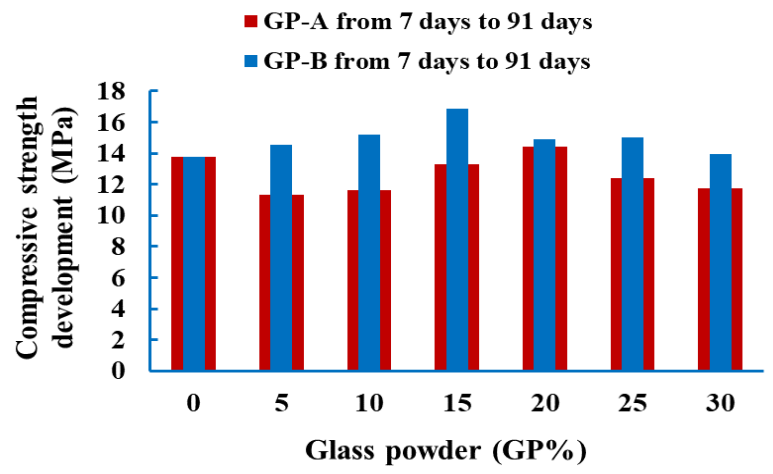

Figure 10. Particle size effect of GP on the development of compressive strength at various replacements

\subsubsection{Splitting tensile strength (ASTM C496 [39])}

Figure 11 shows the effect of the two used PSDs and percentages of GP replacing cement on the splitting strength of concrete on the 28th day. The results generally indicate that the variation in the particle sizes of the GP does not contribute to a significant difference in the values of the concrete tensile strength. One can observe that, with a substitution of up to $15 \%$, the tensile strength of GP-A is slightly higher than that of GP-B even that the particle size of the latter is smaller. However, beyond the 15\% replacement, the effect is reversed. The reason could be that the replacement of GP-A up to $15 \%$ could have dual positive functions, which are, physically, acting as a filler 
material to increase the compactness of the concrete during casting by working with fine particles of the concrete components. At the same time, acting, chemically, as the pozzolanic behavior at the time of hydration. However, beyond which, these features will be minimized. Compared to the control specimen and irrespective of particle size distribution, there is a relatively small reduction in the splitting strength with increasing percentage replacement of GP up to $15 \%$. After that, a noticeable reduction in tensile strength can be observed.

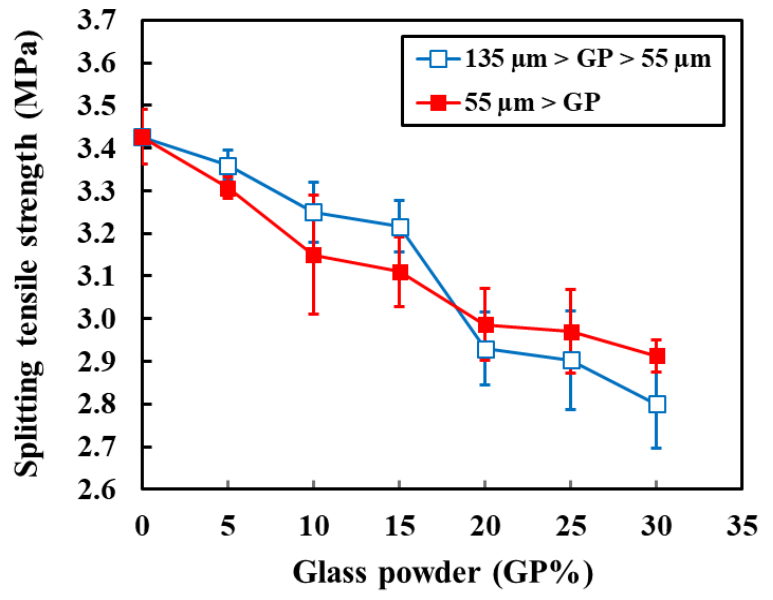

Figure 11. Effect of replacing cement with GP on splitting strength of concrete. The error bars represent the standard deviations of three specimens

\subsubsection{Flexural tensile strength (ASTM C78 [42])}

Figure 12 shows the test results of the flexural strength of concrete containing various percentages and PSD of GP at the age of 28 days. Unlike the splitting tensile strength, up to $20 \%$ replacement, GP-B has high flexural strength compared to GP-A. Beyond that, both types have almost the same values. Compared to the reference concrete, up to $15 \%$ of replacement and for GP-A, the reduction value of flexural tensile strength slightly decreased, which is about $6 \%$. Further reduction, which ranges from $12 \%$ to $14 \%$, can be seen when the dosage of replacement increased from $15 \%$ to $30 \%$. However, the GP-B at $5 \%$ substitution gives flexural strength higher than that provides by the reference concrete. The percentage increase is about $1 \%$. After that, by increasing the amount of replacement from $5 \%$ to $20 \%$ results in a relatively minor decrease in flexural strength, which is $1 \%$ and $7 \%$, respectively. The percentage reduction in the flexural strength is $14 \%$ when the percentage replacements are $25 \%$ and $30 \%$, respectively.

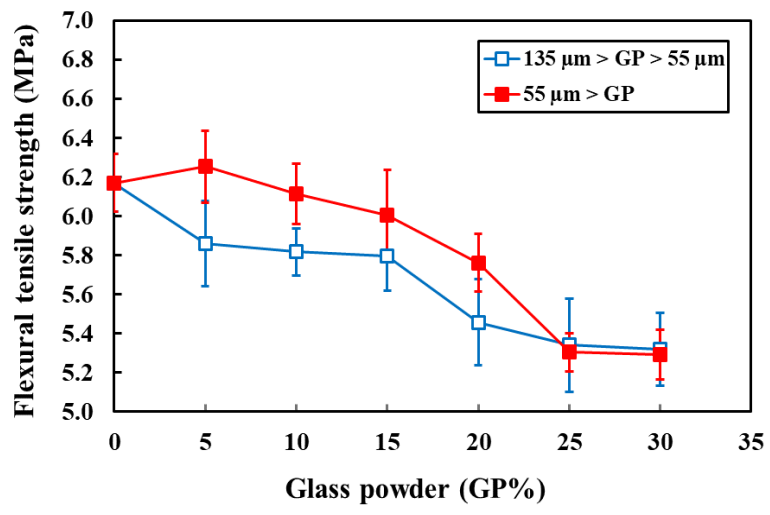

Figure 12. Effect of replacing cement with GP on flexural strength of concrete. The error bars represent the standard deviations of three specimens

\subsection{Model Analysis}

\subsubsection{Compressive strength models}

In this study, two models were developed to predict the compressive strength of GP-concrete. In the first model (Eq.7), two significant parameters, which are the percentage amount of GP and the compressive strength of the control specimen, are considered. Whereas in the second model (Eq.8), the influence of water to binder ratio $(\mathrm{w} / \mathrm{b})$, percentage replacement of GP (GP \%), and curing time (t) are taken into consideration.

$$
\begin{gathered}
f \bar{c}_{(G P)}=A \frac{f \bar{c}_{(N C)}^{a}}{G P^{b}} \\
f \bar{c}_{(G P)}=L\left(\frac{w}{b}\right)^{P}(t)^{Z}+\mathrm{d}\left(\frac{w}{b}\right)^{e}(t)^{f}(G P)^{W}
\end{gathered}
$$

In which $f \bar{c}_{(G P)}$ is the cylindrical compressive strength of GP-concrete in (MPa), $f \bar{c}_{(N C)}$ is the cylindrical compressive strength of concrete without GP in (MPa), $(A, a$, and $b)$, and $L, P, Z, d, w, e$, and $f$ are model parameters of the Equations (7) and (8), respectively. The second model (Eq. 8) is also used to quantify the impact of $\mathrm{w} / \mathrm{b}$, test age $(\mathrm{t})$, and percentage replacement of cement by GP on various mechanical properties of GP-concrete.

The first model (Eq. 7) was proposed by Mohammed [43] for measuring the compression strength of concrete containing recycled PET waste. While the second model (Eq. 8) was previously suggested by Ghafor et al. [37] for predicting different strength behavior of mortar modifies with silica fume and evaluating the effect of curing time, the ratio of water to cement, and the percentage of silica fume on different strength and durability properties of cement mortar with or without silica fume. In the current study, the two mentioned models are developed so that they give the proper relation between dependent and independent variables. 


\subsubsection{Quantification of the effect of different parameters}

To quantify the influence of w/b ratio, curing days ( $t$ ), particle size distributions, and percentage amount of GP (GP \%) on compressive strength, Equation (8) is used. On the basis of the experimental data obtained and through the use of non-linear relationships, Equations (8a) and (8b) were obtained for each particle size of the GP (GP-A and GP-B) used, respectively. The model parameters were estimated by using the Least Squares Method of multiple regression analysis.

$$
\begin{aligned}
f \bar{c}_{(G P) A} & =\frac{10.94 t^{0.1409}}{\left(\frac{w}{b}\right)^{1.476}}-\frac{109.5059 t^{0.0493}(G P)^{1.6853}}{\left(\frac{w}{b}\right)^{0.0466}} \\
f \bar{c}_{(G P) B} & =\frac{10.94 t^{0.1409}}{\left(\frac{w}{b}\right)^{1.476}}-\frac{41.6257 t^{0.0493}(G P)^{1.110}}{\left(\frac{w}{b}\right)^{0.0448}}
\end{aligned}
$$

From the model parameters observed for both Equations (Eqs. 8a and 8b), it can be said that regardless of the particle sizes of GP, the compressive strength is significantly affected by GP\%. This can be observed by investigating the model parameter $w$ in the Equations (8a) and (8b), $w=$ 1.6853 and 1.110 respectively. While $\mathrm{w} / \mathrm{b}$ and curing time are less effective than GP content. By comparing the combined effect of $\mathrm{w} / \mathrm{b}$ and the curing time factors $(f$ and $e$ ) in the Equations (8a) and (8b), $(f=0.0493$ and $e=0.0466)$ and $(f=0.0493$ and $e=0.0448)$ respectively, the $\mathrm{w} / \mathrm{b}$ and curing time have the same impact on the compression strength of both (GP-A and GP-B). There is a reverse proportional relationship between increased compressive strength with an increased percentage of $\mathrm{w} / \mathrm{b}$ and GP.

The comparison of the measured and the predicted compressive strength values for both GP-A and GP-B is shown in Figure 13. One can observe that there is a good relationship between tested and calculated compression strength $\left(\mathrm{R}^{2}=0.97\right.$ and 0.95$)$ for both GP-A and GP-B, respectively. Also, the line of best fit for both GP-A and GP-B is nearly close to each other (Figure 13). This implies the possibility of proposing an Equation for predicting compressive strength without taking into account the size effect of GP. This observation reinforces the experimental results obtained in this study.

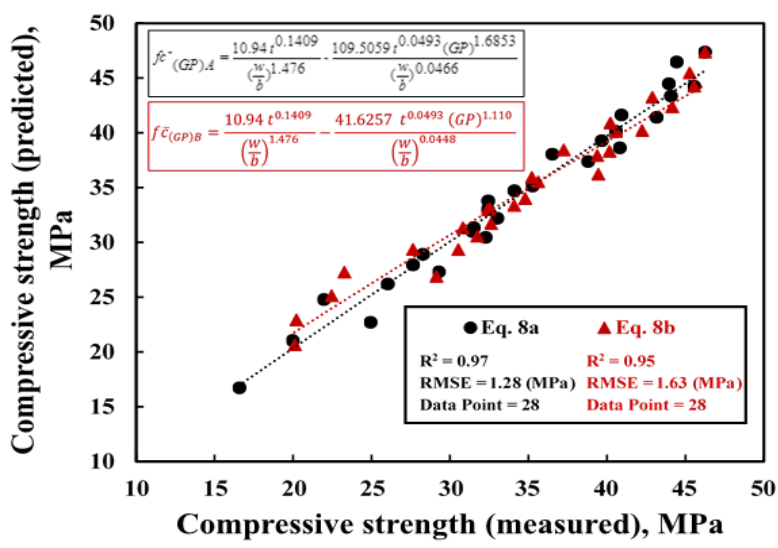

Figure 13. Comparison of the measured and predicted compressive strength of GP-modified concrete using Equations (8a) and (8b).

\subsubsection{The effect of PSD on compressive strength}

From experimental and analytical results, it was observed that the difference in particle size distributions of GP does not have a significant effect on the strength development values of concrete replaced cement with GP up to $25 \%$; therefore, to propose a formula for the prediction of compressive strength without taking into account the particle size effect of GP, Equation (7a) is proposed. The model factors were determined from the Least Squares Method of multiple regression analyses. The relationship between measured and calculated compressive strength by using Equation (7a) with the prediction accuracy is shown in Figure 14.

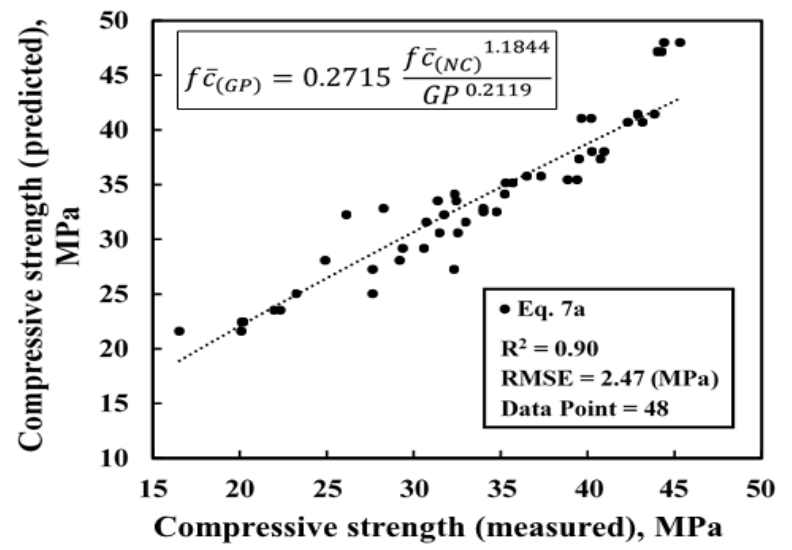

Figure 14. Test and calculated compressive strength using Equation (7a).

To quantify the impact of $w / b$, test age ( $t$ ), and percentage replacement of GP (GP \%) on the compressive strength without considering for particle sizes of GP, Equation (8c) is proposed. Figure 15 shows the relationship between the compressive strength measured and calculated using the Equation (8c).

$$
\begin{gathered}
f \bar{c}_{(G P)}=0.2715 \frac{f \bar{c}_{(N C)}^{1.1844}}{G P^{0.2119}} \\
f \bar{c}_{(G P)}=\frac{10.94 t^{0.1409}}{\left(\frac{w}{b}\right)^{1.476}}-\frac{76.2633 t^{0.0112}(G P)^{1.3855}}{\left(\frac{w}{b}\right)^{0.0483}}
\end{gathered}
$$

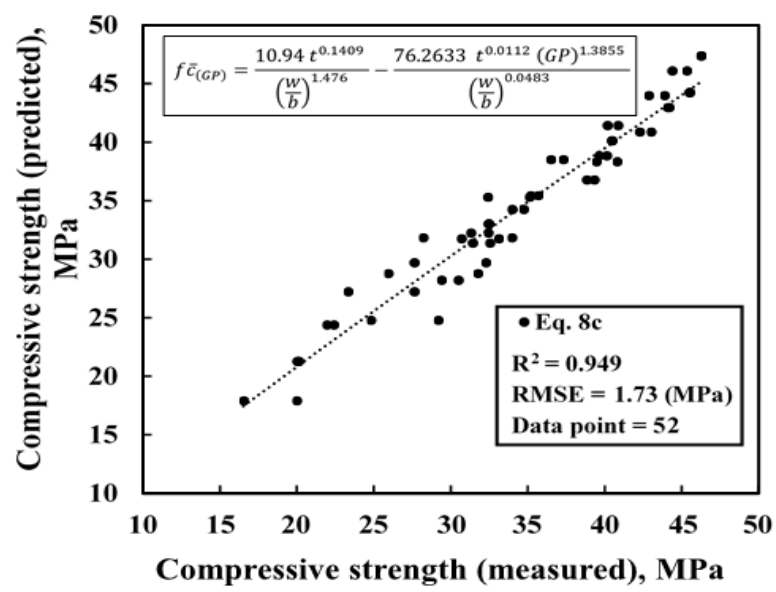

Figure 15. Test and calculated compressive strength using Equation (8c). 
Based on the model parameters $A, a$, and $b(0.2715$, 1.1844, and 0.2119) obtained from Equation (7a), the compressive strength of the GP-concrete is primarily dependent on the combined effect of the compressive strength of the control specimen and GP\%. The considerable effect of the GP on the compressive strength of GP-concrete cannot, therefore, be ignored.

Based on the model factors $e, f$, and $w(0.0483,0.0112$, and 1.3855) obtained from Equation (8c), GP\% has a visible impact on the compressive strength value. While $\mathrm{w} / \mathrm{b}$ and curing age, comparatively, does not have a noticeable effect. It can also be found that the age of the test (curing time) is not a prominent parameter when quantifying the compressive strength of GP-concrete.

The proposed Equation (8c) compared to Equation (7a) has better relationships between predicted and measured compressive strength, as shown in Figure 16.

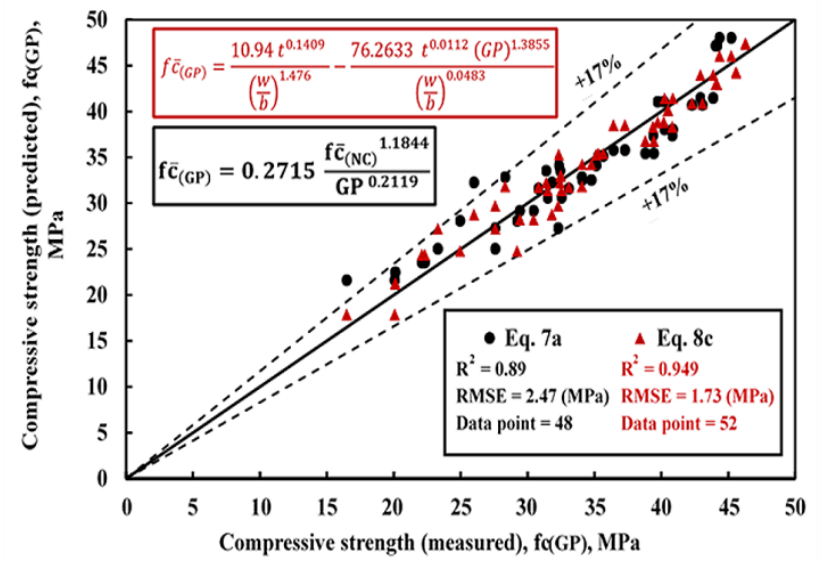

Figure 16. Test and calculated compressive strength using different proposed Equations (7a and 8c)

It is essential to be said that Equation (7a) can only be used to estimate the compressive strength of GP-concrete, while Equation ( $8 \mathrm{c}$ ) can be used to estimate the compressive strength of both normal and GP-concrete. Considering the prediction accuracy of the proposed Equations (7a) and (8c), as shown in Figure 16, they can acceptably predict the compressive strength of GP-concrete.

\subsubsection{The prediction of splitting and flexural strength}

To highlight the role of concrete parameters other than compressive strength, Equation (8) is developed to be used for predicting the splitting tensile strength (Eq. 8d) and the flexural tensile strength (Eq. 8e) of GP-concrete. In both Equations, the effect of the water to binder ratio $(w / b)$ and curing age (t) in addition to the GP content is quantified. However, the impact of the particle size of GP is not taken into consideration. The reason is that, similar to compressive strength, it has a relatively small effect on the values of splitting and flexural tensile strength obtained experimentally.

$$
f t_{(G P)}=\frac{1.5113(t)^{0.1172}}{\left(\frac{w}{b}\right)^{0.7532}}-\frac{0.7975(t)^{0.101}(G P)^{0.8602}}{\left(\frac{w}{b}\right)^{0.5888}}
$$

$$
f r_{(G P)}=\frac{4.1773(t) 0.019}{\left(\frac{w}{b}\right)^{0.5809}}-\frac{0.3138(t)^{0.5695}(G P)^{1.3162}}{\left(\frac{w}{b}\right)^{1.3521}}
$$

Figures 17 and 18 present the comparison between the tested and calculated splitting and flexural tensile strength for the proposed Equations (8d) and (8e), respectively. Also, the accuracy of the proposed Equations was obtained and listed in Table 3. Based on the statistical parameters $\mathrm{R}^{2}$ and RMSE for Equation $8 \mathrm{~d}(0.916$ and 0.059$)$ and Equation $8 \mathrm{e}(0.85$ and 0.13$)$, the two Equations are shown to have an acceptable relationship between the data tested and those predicted.

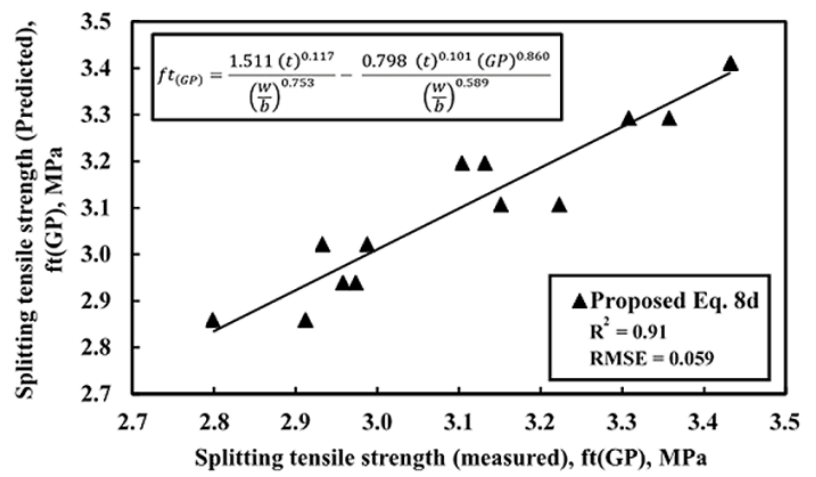

Figure 17. Test and calculated splitting tensile strength using the proposed Equation (8d)

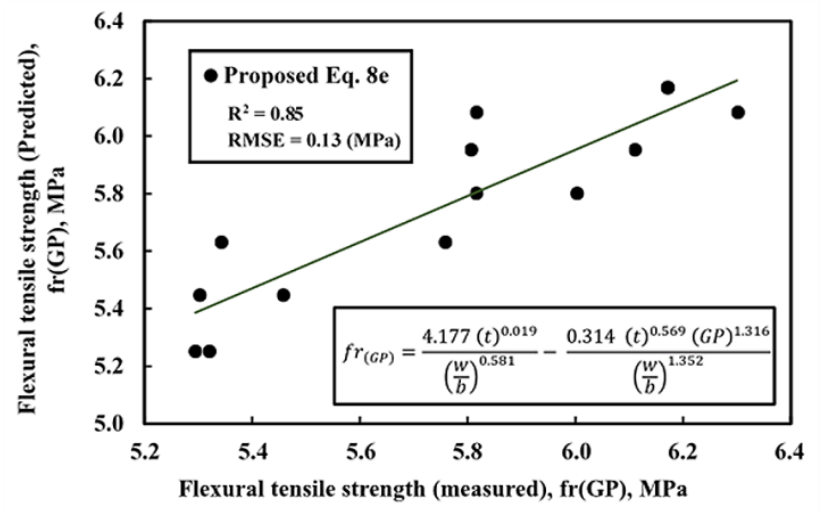

Figure 18. Test and calculated flexural strength using the proposed Equation (8e)

Table 3. Statistical performance measures for the proposed Equations.

\begin{tabular}{cccccc}
\hline $\begin{array}{c}\text { Proposed } \\
\text { Equation }\end{array}$ & $\begin{array}{c}\text { IAE } \\
\mathbf{( \% )}\end{array}$ & $\begin{array}{c}\text { MAE } \\
\mathbf{( M P a )}\end{array}$ & $\begin{array}{c}\text { RMSE } \\
\mathbf{( M P a )}\end{array}$ & $\begin{array}{c}\text { MAPE } \\
\mathbf{( \% )}\end{array}$ & $\begin{array}{c}\text { Fig. } \\
\text { No. }\end{array}$ \\
\hline $\mathbf{8 c}$ & 4.096 & 1.417 & 1.73 & $4.55 \%$ & 15 \\
$\mathbf{8 d}$ & 1.55 & 0.048 & 0.059 & $1.57 \%$ & 17 \\
$\mathbf{1 a}$ & 2.033 & 0.062 & 0.077 & $1.99 \%$ & 19 \\
$\mathbf{2 a}$ & 2.190 & 0.067 & 0.078 & $2.16 \%$ & 19 \\
$\mathbf{8 e}$ & 2.103 & 0.121 & 0.13 & $2.11 \%$ & 18 \\
$\mathbf{1 b}$ & 2.896 & 0.165 & 0.180 & $2.90 \%$ & 20 \\
$\mathbf{2 b}$ & 2.931 & 0.157 & 0.184 & $2.94 \%$ & 20 \\
\hline
\end{tabular}

Based on the constant coefficients obtained for Equations (8d) and (8e), the GP\% is much active than w/b and curing days in changing the splitting and flexural tensile strength of 
GP-concrete. Both $w / b$ and curing days have a similar impact, although their effects on increasing or decreasing the splitting and flexural tensile strength are small.

\subsubsection{Correlation between compressive and splitting strengths}

Based on the analysis of the experimentally obtained data, both Vipulanandan and Hoek-Brown correlation models were developed (Eqs. 1a and 2a) to correlate between compressive strength and splitting tensile strength of GP-concrete (Figure 19).

$$
\begin{array}{r}
f t_{(G P)}=1.6164+\frac{f \bar{c}_{(G P)}}{16.071+0.2087 f \bar{c}_{(G P)}} \\
f t_{(G P)}=f \bar{c}_{(G P)}-0.0551\left(\frac{-0.6179 f \bar{c}_{(G P)}}{-0.0551}-0.9668\right)^{1.0654}
\end{array}
$$

From Figure 19 and depending on the accuracy predictions obtained for both developed models, as shown in Table 3, they have almost the same accuracy. Therefore, both models have nearly the same prediction for the relationship between the compressive strength and the flexural tensile strength of GP-concrete.

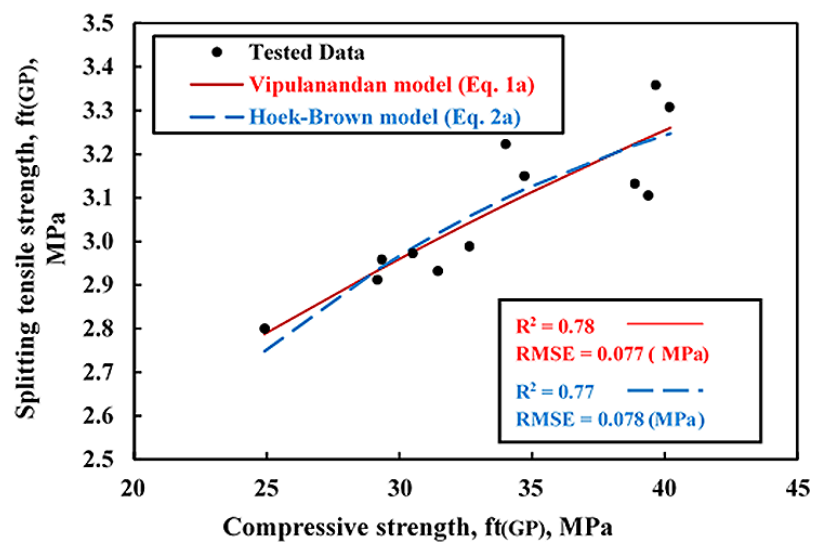

Figure 19. Correlation between compressive strength and splitting strength of GP-concrete

\subsubsection{Correlation between the compressive and flexural tensile strengths}

Likewise splitting tensile strength, Vipulanandan and Hoek-Brown correlation models were developed to represent the variation of the flexural tensile strength $\left(f r_{(G P)}\right)$ with compressive strength $\left(f \bar{c}_{(G P)}\right)$. Equations (1b) and (2b) represent Vipulanandan and Hoek-Brown developed correlation model, respectively

$$
\begin{gathered}
f r_{(G P)}=0.4339+\frac{f \bar{c}_{(G P)}}{2.3482+0.1196 f \bar{c}(G P)} \\
f r_{(G P)}=f \bar{c}_{(G P)}-3.4795\left(-0.655 \frac{f \bar{c}_{(G P)}}{-3.4795}-0.0204\right)^{1.1298}
\end{gathered}
$$

The accuracy performance measures for the two developed models were obtained and summarized in Table 3. The variation of flexural strength with compressive strength was represented by the use of both Equations (1b) and (2b), as shown in Figure 20. Both Equations have nearly the same accuracy for predicting flexural strength as a function of the compressive strength of GP-concrete.

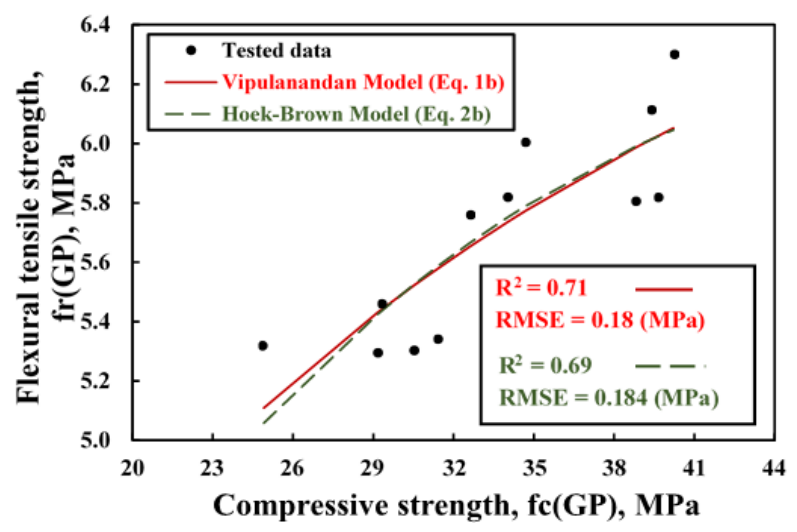

Figure 20. Relationship between compressive strength and flexural tensile strength of GP-concrete

\section{Conclusions}

In this study, the influence of the two different grain size distributions of the same type of waste GP in different percentages $(5 \%$ to $30 \%)$ on the mechanical behavior of concrete was investigated. By using experimentally observed data, various models have been developed to evaluate and correlate different mechanical characteristics of GP-concrete. The comparisons between the proposed Equations were also made.

The following conclusions are drawn based on the experimental and analytical results:

1) The difference in particle size distributions of GP has no significant impact on the values of compressive, splitting, and flexural tensile strength of concrete replaced cement with GP up to $25 \%$, provided that the particle sizes of GP are less than $135 \mu \mathrm{m}$.

2) Whatever the particle sizes of GP and age of test, the strength activity index decreases with increasing GP content. However, the decreasing rate is minimal up to $10 \%$.

3) The acceptable GP content to be used as a cement replacement is $10 \%$ considering compressive strength at 28 days, environmental benefits, and cost-effectiveness. At 28 days of testing, the compressive strength of both particle sizes of GP (GP-A and GP-B) was found slightly lower (approximately $4 \%$ and 3\%, respectively) than the reference concrete specimen. However, at the same age, the acceptable GP\% is $15 \%$ when splitting, and flexural tensile strength is considered.

4) Experimental results indicated that, among different concrete parameters considered, the percentage of cement replacement by GP was found to have more effects on compressive, splitting, and flexural tensile strength compared to its particle size distributions. 
This indication agrees with the analytical results obtained in this study.

5) There is excellent potential for the use of powdered waste glass as a partial replacement for cement in the concrete industry.

6) The particle size effect on the prediction of various strength characteristics of concrete was found to be small so that it can be neglected when it is smaller than $135 \mu \mathrm{m}$.

7) GP \% is much more effective than curing time and $\mathrm{w} / \mathrm{b}$ to decrease or increase the compressive, splitting, and flexural strength of concrete incorporating GP.

8) Both curing days and $w / b$ were found to have similar effects, although their effects on changing the splitting and flexural tensile strength were small.

9) The different strength behavior of GP-modified concrete was well predicted in terms of $w / b$, curing time, and GP\%. The analytical results were in good agreement with the experimental results.

\section{Funding}

This research received no external funding.

\section{Acknowledgments}

The authors are grateful to Ahmed Mohammed, of Sulaimani University, Kurdistan-Iraq, for providing valuable information on the analytical models used in this study.

\section{Conflicts of Interest}

The authors declare no conflict of interest.

\section{REFERENCES}

[1] Mathew B. J., Sudhakar M., Natarajan C., "Strength, economic and sustainability characteristics of coal ashGGBS based geopolymer concrete," International Journal of Computational Engineering Research, vol. 3, no. 1 pp. 207-212, 2013.

[2] Glavind, M. "Sustainability of cement, concrete and cement replacement materials in construction," Sustainability of construction materials. Woodhead Publishing, 2009. 120-147. https://doi.org/10.1533/9781845695842.120

[3] Olivier J. G., Janssens-Maenhout G., Muntean M., Peters J. A. "Trends in global co2 emissions 2016 Report, PBL Netherlands Environmental Assessment Agency, The Hague," PBL publication 2315 (2016).

[4] Nayana A. Y., S. Kavitha, "Evaluation of C02 emissions for green concrete with high volume slag, recycled aggregate, recycled water to build eco environment," International
Journal of Civil Engineering and Technology (IJCIET), vol. 8, no. 5, pp. 703-708, 2017.

[5] Shi C., Zheng K., "A review on the use of waste glasses in the production of cement and concrete," Resources, Conservation and Recycling, vol. 52, no. 2, pp. 234-247, 2007. https://doi.org/10.1016/j.resconrec.2007.01.013

[6] Shi C., Wu Y., Shao Y., Riefler C., "Alkali-aggregate reaction of concrete containing ground glass powder," Proceedings of the 12th International Conference on AAR in Concrete. 2004, pp. 789-795.

[7] Shi C., Wu Y., Riefler C., Wang H., "Characteristics and pozzolanic reactivity of glass powders," Cement and Concrete Research, vol. 35, no. 5, pp. 987-993, 2005. https://doi.org/10.1016/j.cemconres.2004.05.015

[8] Shao Y., Lefort T., Moras S., Rodriguez D., "Studies on concrete containing ground waste glass." cement and concrete research, vol. 30, no. 1, pp. 91-100, 2000. https://doi.org/10.1016/S0008-8846(99)00213-6

[9] Dyer T. D., Dhir R. K., "Chemical reactions of glass cullet used as cement component," Journal of Materials in Civil Engineering, vol. 13, no. 6, pp. 412-417, 2001. https://doi.org/10.1061/(ASCE)0899-1561(2001)13:6(412)

[10] Chen C. H., Huang R., Wu J. K., Yang C. C., "Waste E-glass particles used in cementitious mixtures," Cement and Concrete Research, vol. 36, no. 3, pp. 449-456, 2006. https://doi.org/10.1016/j.cemconres.2005.12.010

[11] Ramezanianpour A.A., "Natural Pozzolans." In Cement Replacement Materials. Springer Geochemistry/Mineralogy. Springer, Berlin, Heidelberg, 2013, pp. 1-46. https://doi.org/10.1007/978-3-642-36721-2_1

[12] Bignozzi M. C., Saccani A., Sandrolini F., "Matt waste from glass separated collection: An eco-sustainable addition for new building materials," Waste management, vol. 29, no.1,

pp. 329-334, 2009.https://doi.org/10.1016/j.wasman.2008.0 2.028

[13] Federico L. M., Chidiac S. E., "Waste glass as a supplementary cementitious material in concrete-critical review of treatment methods," Cement and concrete composites, vol. 31, no. 8, pp. 606-610, 2009. https://doi.org/10.1016/j.cemconcomp.2009.02.001

[14] Shayan A., Xu A. "Value-added utilisation of waste glass in concrete," Cement and concrete research, vol. 34, no. 1, pp. 81-89, 2004. https://doi.org/10.1016/S0008-8846(03)00251 $-5$

[15] Kalakada Z., Doh J.H., "Studies on Recycled Waste Glass Powder as Binder in Concrete," In Wang C., Ho J., Kitipornchai S. (eds) ACMSM25. Lecture Notes in Civil Engineering, vol. 37. Springer, Singapore, 2020, pp. 61-70. https://doi.org/10.1007/978-981-13-7603-0_7

[16] Ramlochan T., Thomas M., Gruber K. A., "The effect of metakaolin on alkali-silica reaction in concrete," Cement and concrete research, vol. 30, no. 3, pp. 339-344, 2000. https://doi.org/10.1016/S0008-8846(99)00261-6

[17] Duchesne J., Bérubé M. A., "The effectiveness of supplementary cementing materials in suppressing expansion due to ASR: another look at the reaction 
mechanisms part 2: pore solution chemistry," Cement and Concrete Research, vol. 24, no. 2, pp. 221-230, 1994. https://doi.org/10.1016/0008-8846(94)90047-7

[18] Du H., Tan K. H., "Use of waste glass as sand in mortar: Part II-Alkali-silica reaction and mitigation methods," Cement and Concrete Composites, vol. 35, no. 1, pp. 118-126, 2013. https://doi.org/10.1016/j.cemconcomp.2012 .08 .029

[19] Du H., Tan K. H., "Effect of particle size on alkali-silica reaction in recycled glass mortars," Construction and Building Materials, vol. 66, pp. 275-285, 2014. https://doi.org/10.1016/j.conbuildmat.2014.05.092

[20] Rajabipour F., Maraghechi H., Fischer G., "Investigating the alkali-silica reaction of recycled glass aggregates in concrete materials," Journal of Materials in Civil Engineering, vol. 22, no. 12, pp. 1201-1208, 2010. https://d oi.org/10.1061/(ASCE)MT.1943-5533.0000126

[21] Schwarz N., Neithalath N., "Influence of a fine glass powder on cement hydration: Comparison to fly ash and modeling the degree of hydration," Cement and Concrete Research,

vol. 38, no. 4, pp. 429-436, 2008. https://doi.org/10.1016/j.c emconres.2007.12.001

[22] Corinaldesi V., Gnappi G., Moriconi G., Montenero A., "Reuse of ground waste glass as aggregate for mortars," Waste Management, vol. 25, no. 2, pp. 197-201, 2005. https://doi.org/10.1016/j.wasman.2004.12.009

[23] Idir R., Cyr M., Tagnit-Hamou A., "Pozzolanic properties of fine and coarse color-mixed glass cullet," Cement and Concrete Composites, vol. 33, no. 1, pp. 19-29, 2011. https://doi.org/10.1016/j.cemconcomp.2010.09.013

[24] Pereira-de-Oliveira L. A., Castro-Gomes J. P., Santos P. M. S., "The potential pozzolanic activity of glass and red-clay ceramic waste as cement mortars components," Construction and Building Materials, vol. 31, pp. 197-203, 2012. https://doi.org/10.1016/j.conbuildmat.2011.12.110

[25] Meyer C., Baxter S., Jin W., "Potential of waste glass for concrete masonry blocks." Materials for the New Millennium. ASCE, pp. 666-673, 1996.

[26] Mirzahosseini M., Riding K. A., "Influence of different particle sizes on reactivity of finely ground glass as supplementary cementitious material (SCM)," Cement and Concrete Composites, vol. 56, pp. 95-105, 2015. https://doi.org/10.1016/j.cemconcomp.2014.10.004

[27] Jiang Y., Ling T-C., Mo K. H., Shi C., "A critical review of waste glass powder-Multiple roles of utilization in cement-based materials and construction products," Journal of environmental management, vol. 242, pp. 440-449, 2019. https://doi.org/10.1016/j.jenvman.2019.04.098

[28] Du H., Tan K. H., "Properties of high volume glass powder concrete," Cement and Concrete Composites, vol. 75, pp. 22-29, 2017. https://doi.org/10.1016/j.cemconcomp.2016.1 0.010

[29] Specification I. S., "No. 5/1984, Portland Cement," Central Organization for Standardization \& Quality Control (COSQC), Baghdad, Iraq, 1984.

[30] ASTM C136 / C136M-14, "Standard Test Method for Sieve Analysis of Fine and Coarse Aggregates," ASTM
International, West Conshohocken, PA, 2014,www.astm.or g. doi: 10.1520/C0136_C0136M-14.

[31] ASTM C33 / C33M-13, "Standard Specification for Concrete Aggregates," ASTM International, West Conshohocken, PA, 2013, www.astm.org. doi: 10.1520/C0033 C0033M-13.

[32] ASTM C192 / C192M-15, "Standard Practice for Making and Curing Concrete Test Specimens in the Laboratory," ASTM International, West Conshohocken, PA, 2015, www.astm.org. doi:10.1520/C0192_C0192M-15.

[33] Mohammed A. S., "Vipulanandan models to predict the mechanical properties, fracture toughness, pulse velocity and ultimate shear strength of shale rocks," Geotechnical and Geological Engineering, vol. 37, no. 2, pp. 625-638, 2019. https://doi.org/10.1007/s10706-018-0633-5

[34] Mohammed A. S., Vipulanandan C, "Compressive and tensile behavior of polymer treated sulfate contaminated CL soil," Geotechnical and Geological Engineering, vol. 32, no. 1, pp. 71-83, 2014. https://doi.org/10.1007/s10706-013-969 2-9

[35] Mohammed A., Vipulanandan C., "Testing and modeling the short-term behavior of lime and fly ash treated sulfate contaminated CL soil," Geotechnical and Geological Engineering, vol. 33, no. 4, pp. 1099-1114, 2015. https://doi.org/10.1007/s10706-015-9890-8

[36] Hoek E., Carranza-Torres C., Corkum B., "Hoek-Brown failure criterion-2002 edition," Proceedings of NARMS-Tac vol 1, no. 1, pp. 267-273, 2002.

[37] Ghafor K., Qadir S., Mahmood W., Mohammed A., "Statistical variations and new correlation models to predict the mechanical behaviour of the cement mortar modified with silica fume," Geomechanics and Geoengineering, pp. 1-13, 2020. https://doi.org/10.1080/17486025.2020.171408 3

[38] ASTM C39 / C39M-15a, "Standard Test Method for Compressive Strength of Cylindrical Concrete Specimens,"ASTM International, West Conshohocken, PA, 2015, www.astm.org. doi:10.1520/C0039_C0039M-15A

[39] ASTM C496 / C496M-11, "Standard Test Method for Splitting Tensile Strength of Cylindrical Concrete Specimens," ASTM International, West Conshohocken, PA, 2004, www.astm.org. doi:10.1520/C0496_C0496M-11

[40] Letelier V., Henríquez-Jara B. I., Manosalva M., Parodi C., Ortega J. M., "Use of waste glass as a replacement for raw materials in mortars with a lower environmental impact," Energies, vol. 12, no. 10, 1974, 2019. https://doi.org/10.3390/en12101974

[41] He Z. H., Zhan P. M., Du S. G., Liu B. J., Yuan W. B. "Creep behavior of concrete containing glass powder," Composites Part B: Engineering, vol. 166, pp. 13-20, 2019. https://doi.org/10.1016/j.compositesb.2018.11.133

[42] ASTM C78 / C78M-15a, "Standard Test Method for Flexural Strength of Concrete (Using Simple Beam with Third-Point Loading)," ASTM International, West Conshohocken, PA, 2015, www.astm.org. doi:10.1520/C00 78_C0078M-15A

[43] Mohammed A. A., "Flexural behavior and analysis of 
reinforced concrete beams made of recycled PET waste concrete," Construction and Building Materials, vol. 155, pp.

593-604, 2017. https://doi.org/10.1016/j.conbuildmat.2017. 08.096

[44] ASTM C618-15, "Standard Specification for Coal Fly Ash and Raw or Calcined Natural Pozzolan for Use in
Concrete," ASTM International, West Conshohocken, PA, 2015, www.astm.org

[45] Rahman S., Uddin M. N., "Experimental Investigation of Concrete with Glass Powder as Partial Replacement of Cement," Civil Engineering and Architecture, Vol. 6, No. 3, pp. 149 - 154, 2018.https://doi.org/10.13189/cea.2018.0603 04 